\title{
ANÁLISE MICROBIOLÓGICA E CARACTERIZAÇÃO DE POTENCIAIS PATÓGENOS ASSOCIADOS A DETERMINADOS COSMÉTICOS
}

\author{
Rogério Philippov de Oliveira ${ }^{1}$ \\ Carlos Alberto Tellez Soto ${ }^{2}$ \\ Aírton Abrahão Martin ${ }^{3}$
}

\begin{abstract}
Resumo: Neste trabalho se avaliaram por meio de experimentos microbiológicos e por análise espectral por meio da Reflectância Total Atenuada - RTA, as condições higiênicas e físico-químicas em relação à possível contaminação e caracterização de micro-organismos patogênicos em produtos cosméticos do tipo hidratante corporal para adultos. Esta pesquisa aborda, o mecanismo de ação como também o efeito bacteriostático e bactericida do fármaco Triclosan, presente na formulação de 2 dos hidratantes corporais a serem analisados, visto que bactérias patogênicas presentes em cosméticos podem acarretar grandes danos aos indivíduos. Pouco se tem divulgado na literatura nacional, o assunto ligado à temática. Neste sentido, torna-se importante o desenvolvimento desta linha de pesquisa.

Palavras-chave: Cosméticos; Micro-organismos; Antibiograma; Reflectância Total Atenuada - RTA.
\end{abstract}

\footnotetext{
1 Faculdade de Ciências da Saúde/Universidade do Vale do Paraíba, Brasil. E-mail: rogeriobiomedicina@gmail.com.

2 Faculdade de Ciências da Saúde/Universidade do Vale do Paraíba, Brasil. E-mail: cayotellez@gmail.com.

${ }^{3}$ Faculdade de Ciências da Saúde/Universidade do Vale do Paraíba, Brasil. E-mail: amartin@univap.br.
} 